\title{
21-day Balneotherapy Improves Cardiopulmonary Function and Physical Capacity of Pilots
}

\author{
Li Xu' ${ }^{1,2)}$, RunZe $\mathrm{ShI}^{3)}$, Bing WanG ${ }^{4)}$, Jie GenG ${ }^{2)}$, Linfu Zhou ${ }^{1)}$, Yugang Zhang ${ }^{3)}$, \\ Guanghui Guo ${ }^{1)}$, Jingzao Chen ${ }^{2)}$, Xinsheng $\mathrm{CAO}^{2)}$, Shu Zhang ${ }^{4)}$ \\ 1) Department of Medical Affairs, Lintong Sanatorium of Lanzhou Military Region \\ 2) Department of Aerospace Biodynamics, Fourth Military Medical University \\ 3) Department of Health, Lanzhou Military Region \\ 4) The Key Laboratory of Aerospace Medicine, Chinese Ministry of Education: Xi'an 710032, China. \\ TEL:+8629-8324-3218,E-mail: shuzhang89@hotmail.com
}

\begin{abstract}
Purpose] The purpose of this study was to investigate the effects of balneotherapy on the cardiopulmonary function and physical capacity of pilots. [Subjects] Thirty-six healthy male pilots were recruited. [Methods] All subjects received entire-body immersion bath therapy in thermomineral water for $30 \mathrm{~min}$ a day for 21 days. Electrocardiograms, carotid pulse traces, and phonocardiograms were recorded using a cardiac function measuring device. Pulmonary function tests were performed using a Pony FX spirometer. The physical capacity of pilots was examined 1 day before and after balneotherapy. [Results] After 21 days of treatment, isovolumetric contraction time and the ratio of isovolumetric contraction time/left ventricular ejection time were reduced. Forced vital capacity, peak expiratory flow, the ratio of forced expiratory volume in 1 second/ forced expiratory volume and forced expiratory flow at $25-75 \%$ were elevated. The exercise numbers of pull-ups and sit-ups in 1 min were boosted. [Conclusion] The findings imply that balneotherapy for 21 days has a significant effect on the cardiopulmonary function and physical capacity of pilots.

Key words: Balneotherapy, Cardiopulmonary function, Physical capacity
\end{abstract}

(This article was submitted Aug. 21, 2012, and was accepted Oct. 2, 2012)

\section{INTRODUCTION}

Balneotherapy, also known as medical hydrology, or thermal therapy, dates back to the dawn of civilization ${ }^{1)}$. It is based on belief in the healing properties of natural mineral and thermal waters. Balneotherapy involves the immersion of the body in mineral water baths or pools. Mineral waters are natural solutions formed under specific geologic conditions and characterized by a "chemico-physical dynamism"2) They originate in springs, are bacteriologically pure, and have therapeutic potential. Balneotherapy is popular for the treatment of various musculoskeletal conditions in Europe, Japan and China. There is some evidence that balneotherapy of various kinds might be helpful for ankylosing spondylitis, fibromyalgia, low back pain, osteoarthritis, psoriasis, rheumatoid arthritis and varicose veins ${ }^{1,3,4)}$. In addition to the treatment of these ailments, balneotherapy is widely utilized in the health promotion of pilots, as an important part of natural remedies in China.

Pilots are often forced to deviate from their normal work/ sleep schedules by flight operations that involve irregular work hours, night flights, early starts or transmeridian flights ${ }^{5-7)}$. With the improvement of aircraft performance and the lengthening of flying missions, the physical and psychological loads experienced by crew have increased, disrupting their biological rhythms, possibly leading to cardiopul- monary dysfunction, flight fatigue, chronic insomnia, cervical and lumbar disorders ${ }^{8,9)}$. This sub-optimal health state could imperil the health and safety of pilots. To avoid the occurrence of these conditions and promote the health of pilots, a series of measures can be employed such as regular physical examinations and natural remedies. Natural therapy includes convalescence modalities such as mineral spring balneotherapy, and climatotherapy landscape convalescence. Balneotherapy is a comprehensive treatment for persons with disease or sub-optimal health status. It is used to prevent disease and restore health, and has been widely used in health promotion for pilots in China since 1955.

China is a country with rich resources of mineral springs. Lintong mineral spring is one of the most famous springs. It contains many kinds of chemical constituents, such as radon, potassium, sodium, calcium and magnesium ${ }^{10,11)}$. Because of its high medical value, Lintong spring is very suitable for carrying out balneotherapy. For over 6,000 years the general curative powers and therapeutic advantages of Lintong mineral spring have been well recognized. The modern era for the health improvement of pilots at Lintong mineral spring began in the 1950s, and Lintong district has become a very famous place for sanatoriums since then. Over 10,000 pilots have received recuperation (mineral spring bath, climatotherapy, landscape convalescence, etc) at Lintong Sanatorium and most of them have been satisfied with the 
Table 1. Mineral analysis of Lintong mineral spring water

\begin{tabular}{|c|c|c|c|c|c|c|c|c|c|}
\hline \multirow[t]{2}{*}{$\mathrm{pH}$} & \multirow{2}{*}{$\begin{array}{l}\text { TOTAL mineral } \\
\left(\mathrm{mg} \cdot \mathrm{L}^{-1}\right)\end{array}$} & \multicolumn{4}{|c|}{ Anions $\left(\mathrm{mg} \cdot \mathrm{L}^{-1}\right)$} & \multicolumn{4}{|c|}{ Cations $\left(\mathrm{mg} \cdot \mathrm{L}^{-1}\right)$} \\
\hline & & $\mathrm{Cl}^{-}$ & $\mathrm{HCO}_{3}^{-}$ & $\mathrm{SO}_{4}{ }^{2-}$ & $\mathrm{F}^{-}$ & $\mathrm{Ca}^{++}$ & $\mathrm{Mg}^{++}$ & $\mathrm{Na}^{+}$ & $\mathrm{K}^{+}$ \\
\hline 7.7 & 1251.2 & 193.2 & 384.5 & 277.2 & 3.5 & 33.9 & 14.2 & 326.5 & 3.4 \\
\hline
\end{tabular}

results of the treatments for chronic diseases or sub-optimal health conditions. However, until now, few in-depth studies focusing on the effectiveness of balneotherapy for the health improvement of pilots have been published. The main aim of the present study was to determine the effectiveness of balneotherapy on the cardiopulmonary function and physical capacity of pilots.

\section{SUBJECTS AND METHODS}

This study was performed at the Lintong Sanatorium of Lanzhou Military Region in 2010. Thirty-six healthy male pilots with a mean (range) age of $31 \pm 5 \mathrm{yr}$, body weight of $69 \pm 7 \mathrm{~kg}$ and height of $169 \pm 4 \mathrm{~cm}$, who routinely took four-week vacations, participated in this study. All subjects were in good health without alcoholic or tobacco addiction, and had no history of diabetes mellitus, hypertension, heart failure, valvular heart disease, cardiomyopathies, atrial fibrillation, coronary artery disease, asthma, chronic obstructive lung disease or psychiatric diseases. None of the subjects had upper limb or spine pathologies, or rheumatological or neurological conditions.

The subjects were fully informed of the purpose of this study and contents, and individually agreed to participate in the therapy program. The study protocol was approved in advance by the Fourth Military Medical University Human Research Ethics Committee. Informed consent was received from all of the participants in the experiment.

All subjects spent 21 days at the Lintong Sanatorium. During this period, they received daily entire-body immersion bath therapy (once a day, $30 \mathrm{~min}$ ) in the thermal water $\left(35-37^{\circ} \mathrm{C}\right.$ from Day 1 to Day $7,38-40{ }^{\circ} \mathrm{C}$ from Day 8 to Day 21). The details of the analysis of the thermomineral water used in the balneotherapy are listed in Table 1.

Cardiac function was assessed by the same physicians 1 day before and after the balneotherapy treatment. Subjects were allowed to lie down and rest for 20 minutes, before electrocardiograms, carotid pulse traces, and phonocardiograms were simultaneously recorded using a cardiac function measuring device (Zhenqin Ltd., Xi'an, China). Indices of cardiac pump function included stroke volume (SV), cardiac output (CO), cardiac index (CI) and total peripheral resistance (TPR). Indices of heart contractive function included left ventricular ejection time (LVET), pre-ejection period (PEP), PEP/LVET, isovolumetric contraction time (ICT), ICT/LVET, ejection fraction (EF).

Pulmonary function tests were routinely performed using a Pony FX spirometer (COSMED, Italy) in the morning. The pilots sat quietly and breathed smoothly until the test began. Maximum voluntary ventilation (MVV), forced vital capacity (FVC), forced expiratory volume (FEV), forced expiratory volume in 1 second $\left(\mathrm{FEV}_{1}\right) / \mathrm{FVC}$, peak expiratory flow (PEF) and forced expiratory flow at $25-75 \%$ $\left(\mathrm{FEF}_{25-75 \%}\right)$ were recorded as indices of pulmonary function.

The physical capacity of pilots was examined 1 day before and after the balneotherapy. The following items were assessed: pull-ups, free-weight squats, sit-ups and body mass index. A pull-up is a closed-chain bodyweight movement in which the subject hangs from a pull-up bar with straight arms and pulls up until the chin passes the bar. The subjects were encouraged to do as many pull-ups as possible without time limit.

When performing free-weight squats, a bar with weights $(50 \mathrm{~kg})$ was placed across the shoulder blades. The subjects stood with their feet apart at shoulder width and made sure the load was dispersed equally through all the joints. There should be a simultaneous bending of the knee, hip and ankle joints. While bending down, the trunk was maintained in a neutral posture throughout by keeping the chest up. On reaching the point of maximum descent, the subject begins upward movement. The maximum number of squats with no time limit was recorded as the result.

When beginning the sit-up, subject lay with their backs on the floor and their hands behind their heads. The knees were bent to reduce stress on the back muscles and spine. Then, the subject elevated both the upper and lower vertebrae from the floor until everything superior to the buttocks was not touching the ground. The subject repeated this movement as many times as possible in $1 \mathrm{~min}$.

The body mass index (BMI) is a heuristic proxy for human body fat that is based on an individual's weight and height. BMI is defined as the individual's body mass divided by the square of his height. BMI is universally used in medicine and has a unit of measure of $\mathrm{kg} / \mathrm{m}^{2}$.

Data are presented as mean values $\pm \mathrm{SD}$. For the evaluation of statistical differences, the paired two-sample t-test was used. Significance was accepted for $p$ values of less than 0.05 .

\section{RESULTS}

The 21-day balneotherapy treatment had significant effects on the cardiac pump function. $\mathrm{CO}, \mathrm{CI}, \mathrm{EF}$ and TPR showed trends of decrease. SV, LVET, PEP and PEP/LVET showed slight increases after balneotherapy treatment, but the changes were not statistically significant. In contrast, ICT decreased by $13.5 \%(\mathrm{p}<0.05)$ and the ratio of ICT/ LVET decreased by $15.4 \%(\mathrm{p}<0.05)$ after 21 days of balneotherapy (Table 2).

FVC, PEF and $\mathrm{FEF}_{25-75 \%}$ significantly increased after balneotherapy treatment $(\mathrm{p}<0.05)$, while MVV and FEV showed increasing tendencies. Furthermore, $\mathrm{FEV}_{1} / \mathrm{FVC}$ 
Table 2. Changes in cardiac functions of the pilots after balneotherapy treatment $(\overline{\mathrm{x}} \pm \mathrm{s}, \mathrm{n}=36)$

\begin{tabular}{lcc}
\hline Parameter & Pre-balneotherapy & Post-balneotherapy \\
\hline $\mathrm{SV}(\mathrm{ml}$ & $91.48 \pm 31.16$ & $91.94 \pm 38.98$ \\
$\mathrm{CO}\left(\mathrm{L} \cdot \mathrm{min}^{-1}\right)$ & $6.06 \pm 2.20$ & $5.85 \pm 2.24$ \\
$\mathrm{CI}$ & $3.39 \pm 1.16$ & $3.28 \pm 1.21$ \\
TPR $\left(\right.$ dyne $\left.\cdot \mathrm{s} \cdot \mathrm{cm}^{-5}\right)$ & $1251.33 \pm 423.52$ & $1243.38 \pm 427.16$ \\
LVET $(\mathrm{ms})$ & $297.09 \pm 18.70$ & $299.37 \pm 16.84$ \\
PEP $(\mathrm{ms})$ & $77.14 \pm 10.36$ & $79.41 \pm 7.74$ \\
PEP/LVET & $0.26 \pm 0.03$ & $0.26 \pm 0.04$ \\
$\mathrm{ICT}(\mathrm{ms})$ & $39.55 \pm 5.61$ & $34.21 \pm 5.89 *$ \\
$\mathrm{ICT} / \mathrm{LVET}$ & $0.13 \pm 0.02$ & $0.11 \pm 0.02 *$ \\
EF & $0.80 \pm 0.03$ & $0.79 \pm 0.01$ \\
\hline
\end{tabular}

* $\mathrm{p}<0.05$ as compared with pre-balneotherapy. SV, stroke volume; $\mathrm{CO}$, cardiac output; CI, cardiac index; TPR: total peripheral resistance; LVET: left ventricular ejection time; PEP, pre-ejection period; ICT, isovolumetric contraction time; $\mathrm{EF}$, ejection time.

also showed an increase, and the change was statistically significant $(\mathrm{p}<0.01$, Table 3$)$.

The number of pull-ups and sit-ups in $1 \mathrm{~min}$ increased significantly $(7.5 \%, 6.2 \%$, respectively, $\mathrm{p}<0.01)$ after 21 days of balneotherapy (Table 4). In addition, the number of free-weight squats showed a trend of increase, while BMI showed a decreasing tendency.

\section{DISCUSSION}

In this study, 21-day balneotherapy improved cardiac function by reducing ICT and ICT/LVET, improved pulmonary functions through increase of FVC, PEF, $\mathrm{FEF}_{25-75 \%}$ and $\mathrm{FEV}_{1} / \mathrm{FVC}$, and boosted the physical capacity of the pilots. Our findings provide experimental evidence that 21-day balneotherapy influences two physiologically important cardiopulmonary functions and plays a major role in health promotion for pilots.

Balneotherapy can increase venous return by hydrostatic pressure, and warm water immersion can also help to increase early diastolic filling, facilitating improvement in cardiac function $^{12,13)}$. Furthermore, several studies have suggested that balneotherapy can stimulate vascular relaxation, thereby improving vascular function and reducing peripheral vascular resistance and cardiac load ${ }^{14,15)}$. Our findings are in agreement with these previous findings. In our study, balneotherapy decreased ICT and ICT/LEVT, indicating improvement of the left ventricular pump function ${ }^{16,17)}$. Other indicators of the left ventricular pump function, such as LEVT and PEP, showed trends of improvement in cardiac function following balneotherapy, though the differences were not significant. The underlying mechanisms of these alterations in cardiac function, including the roles of autonomic nervous system and humoral factors, need to be further elucidated by future study.

Recently, several authors studied the effectiveness of balneotherapy for the respiratory systems of patients. Balneotherapy was shown to provide significant and longer-
Table 3. Changes in pulmonary functions of the pilots after balneotherapy treatment $(\overline{\mathrm{x}} \pm \mathrm{s}, \mathrm{n}=36)$

\begin{tabular}{lcc}
\hline Parameter & Pre-balneotherapy & Post-balneotherapy \\
\hline MVV (L) & $166.09 \pm 13.87$ & $172.91 \pm 11.48$ \\
FVC (L) & $4.23 \pm 0.61$ & $4.91 \pm 0.54 *$ \\
FEV (L) & $3.87 \pm 0.54$ & $3.94 \pm 0.46$ \\
$\mathrm{FEV}_{1} / \mathrm{FVC}$ & $0.92 \pm 0.06$ & $1.08 \pm 0.07^{* *}$ \\
$\mathrm{PEF}_{\left(\mathrm{L} \cdot \mathrm{s}^{-1}\right)}$ & $8.25 \pm 1.74$ & $9.85 \pm 2.09 *$ \\
$\mathrm{FEF}_{25 \sim 75 \%}(\mathrm{~L})$ & $5.15 \pm 1.25$ & $6.03 \pm 1.34 *$ \\
\hline
\end{tabular}

$* \mathrm{p}<0.05,{ }^{* *} \mathrm{p}<0.01$ as compared with pre-balneotherapy. MVV, maximum voluntary ventilation; FVC, forced vital capacity; FEV, forced expiratory volume; FEV1, forced expiratory volume in 1 second; PEF, peak expiratory flow; $\mathrm{FEF}_{25 \sim 75 \%}$, forced expiratory flow at $25-75 \%$.

Table 4. Changes in physical capacity of the pilots after balneotherapy treatment $(\overline{\mathrm{x}} \pm \mathrm{s}, \mathrm{n}=36)$

\begin{tabular}{lcc}
\hline Parameter & Pre- balneotherapy & Post- balneotherapy \\
\hline $\begin{array}{l}\text { Pull-up } \\
\text { (number) }\end{array}$ & $15.75 \pm 0.58$ & $16.94 \pm 0.93 *$ \\
$\begin{array}{l}\text { Free-weight squat } \\
\text { (number) }\end{array}$ & $18.79 \pm 1.17$ & $19.59 \pm 1.80$ \\
$\begin{array}{l}\text { Sit-up } \\
\text { (number) }\end{array}$ & $30.56 \pm 1.53$ & $32.44 \pm 1.50 *$ \\
BMI & $23.18 \pm 0.63$ & $23.16 \pm 0.77$ \\
\hline
\end{tabular}

* $\mathrm{p}<0.05$ as compared with pre-balneotherapy. BMI, body mass index.

lasting improvement of respiratory symptoms ${ }^{18,19)}$. Our current results were consistent with the results of these studies. In contrast to the slight improvements in patients, remarkable changes in pulmonary function were observed in the pilots. We suggest three possible explanations. First, the hydrostatic pressure of the water on the chest prompted the pilots to increase their tidal volume and in turn this exercised their respiratory muscles. Second, the mineral water contains a high concentration of carbonic acid. Under the action of the carbonic acid gas in the lungs during balneotherapy, breathing becomes deeper and slower improving the ventilation function. Third, hydrostatic pressure may force the diaphragm to move further upwards, resulting in an increase in pulmonary ventilation and expiratory volume. The enhancement of lung function in the pilots may have beneficial effects on their flight training and performance.

In this study, the physical capacity of the pilots was significantly improved by balneotherapy, especially the exercise numbers of pull-ups and sit-ups, whereas BMI showed no significant difference. Many studies have suggested balneotherapy can improve the exercise capacity of patients ${ }^{20-22)}$. The beneficial adaptive responses of the physical capacity of the pilots may have resulted from the thermal effects of balneotherapy. It is known that thermal water promotes dilation of blood vessels, and increases blood oxygenation and metabolic rate. These effects would increase oxygen supply to the skeletal muscles, which would facilitate muscular improvement. The increase 
in physical capacity seen in this study is in accord with other findings that leg immersion in warm water increases maximal voluntary contraction force and jump height ${ }^{23}$. In addition, warm water immersion has also been reported to affect indirect markers of muscle damage, decreasing blood creatine kinase activity and muscle soreness within 72 hours after stretch-shortening exercise ${ }^{23}$. Therefore, our results indicate that balneotherapy has some favourable influence on the restoration of the muscle functions of pilots.

In summary, we investigated the possible benefits of balneotherapy for cardiopulmonary function and physical capacity of pilots. We found that 21-day balneotherapy was effective at improving two physiologically important cardiopulmonary functions. Our results confirm that balneotherapy had beneficial effects, promoting the health of pilots during their vacation at the Lintong Sanatorium. The findings of this study provide a basis for further investigation of the use of balneotherapy as a natural remedy for pilots. The appropriate balneotherapy duration and the most effective regimen of different thermal loads involved in this balneotherapy method are under investigation.

\section{ACKNOWLEDGEMENT}

The authors gratefully thank the aircrew who participated in the study. L XU, RZ SHI, B WANG and J GENG contributed equally to this study. This study was accomplished under the guidance of corresponding authors XS Cao and S Zhang. This work was financially supported by the Defense Medical Foundation of China (Grant No. CLZO9R10, 08G107).

\section{REFERENCES}

1) Nasermoaddeli A, Kagamimori S: Balneotherapy in medicine: a review. Environ Health Prev Med, 2005, 10: 171-179. [Medline] [CrossRef]

2) Lotti $T$, Ghersetich I: Le basi della dermocosmetologia termale. In: Manuale di Dermocosmetologia. Milan: Raffaello Cortina, 1995, pp 751-762.

3) Kamioka H, Tsutani $\mathrm{K}$, Okuizumi $\mathrm{H}$, et al.: Effectiveness of aquatic exercise and balneotherapy: a summary of systematic reviews based on randomized controlled trials of water immersion therapies. J Epidemiol, 2010, 20: 2-12. [Medline] [CrossRef]

4) Verhagen AP, de Vet HC, de Bie RA, et al.: Taking baths: the efficacy of balneotherapy in patients with arthritis. A systematic review. J Rheumatol, 1997; 24: 1964-1971.

5) Ariznavarreta C, Cardinali DP, Villanua MA, et al.: Circadian rhythms in airline pilots submitted to long-haul transmeridian flights. Aviat Space Environ Med, 2002, 73: 445-455. [Medline]

6) Shub Y, Lewy $\mathrm{H}$, Ashkenazi IE: Circadian pattern of simulated flight performance of pilots is derived from ultradian components. Chronobiol Int, 2001, 18: 987-1003. [Medline] [CrossRef]

7) Sparaco P: Combating fatigue to enhance safety. Aviat Week Space Technol, 1996, 145: 49, 53-55. [Medline]

8) Gao YX, Wang L: Analysis on sub-healthy state in pilots. Chin J Conval Med, 2009, 18: 323-324.

9) Weng LY, Zhao B, Li N, et al.: Analysis on military aircrew's sub-health state and its influencing factors. Nurs J Chin PLA, 2010, 27: 1783-1785.

10) Zhang JX, Wang Y, Ren GZ, et al.: Investigation of resources of mineral water in lintong recuperation district. Chin J Conval Med, 2005, 14 411-414.

11) $\mathrm{Xu} \mathrm{L}$, Guo GH, Zhang B: Investigation of natural convalescent factors in Lintong sanitariums. Chin J Conval Med, 2009, 18: 865-869.

12) Cider A, Svealv BG, Tang MS, et al.: Immersion in warm water induces improvement in cardiac function in patients with chronic heart failure. Eur J Heart Fail, 2006, 8: 308-313. [Medline] [CrossRef]

13) Caminiti G, Volterrani M, Marazzi G, et al.: Hydrotherapy added to endurance training versus endurance training alone in elderly patients with chronic heart failure: a randomized pilot study. Int J Cardiol, 2011, 148: 199-203. [Medline] [CrossRef]

14) Tei C, Horikiri Y, Park JC, et al.: Acute hemodynamic improvement by thermal vasodilation in congestive heart failure. Circulation, 1995, 91: 2582-2590. [Medline] [CrossRef]

15) Cider A, Sunnerhagen KS, Schaufelberger M, et al.: Cardiorespiratory effects of warm water immersion in elderly patients with chronic heart failure. Clin Physiol Funct Imaging, 2005, 25: 313-317. [Medline] [CrossRef]

16) Hirschfeld S, Meyer R, Korfhagen J, et al.: The isovolumic contraction time of the left ventricle. An echographic study. Circulation, 1976, 54: 751-756. [Medline] [CrossRef]

17) Yilmaz A, Yalta K, Turgut OO, et al.: Comparison of myocardial performance index versus ratio of isovolumic contraction time/ejection time in left ventricular systolic dysfunction. Adv Ther, 2007, 24: 1061-1067. [Medline] [CrossRef]

18) Aydemir K, Tok F, Peker F, et al.: The effects of balneotherapy on disease activity, functional status, pulmonary function and quality of life in patients with ankylosing spondylitis. Acta Reumatol Port, 2010, 35: 441-446. [Medline]

19) Kesiktas N, Karagulle Z, Erdogan N, et al.: The efficacy of balneotherapy and physical modalities on the pulmonary system of patients with fibromyalgia. J Back Musculoskelet Rehabil, 2011, 24: 57-65. [Medline]

20) Evcik D, Kavuncu V, Yeter A, et al.: The efficacy of balneotherapy and mud-pack therapy in patients with knee osteoarthritis. Joint Bone Spine, 2007, 74: 60-65. [Medline] [CrossRef]

21) Cider A, Schaufelberger M, Sunnerhagen KS, et al.: Hydrotherapy-a new approach to improve function in the older patient with chronic heart failure. Eur J Heart Fail, 2003, 5: 527-535. [Medline] [CrossRef]

22) Crevenna R, Schneider B, Mittermaier C, et al.: Implementation of the Vienna Hydrotherapy Group for Laryngectomees-a pilot study. Support Care Cancer, 2003, 11: 735-738. [Medline] [CrossRef]

23) Skurvydas A, Kamandulis S, Stanislovaitis A, et al.: Leg immersion in warm water, stretch-shortening exercise, and exercise-induced muscle damage. J Athl Train, 2008, 43: 592-599. [Medline] [CrossRef] 